\title{
Educational ecological architecture
}

\author{
S. C. Santos ${ }^{1}$, G.Klein ${ }^{2}$ \& M. Despang ${ }^{3,4}$ \\ ${ }^{1}$ School of Architecture, CESUGA, University College Dublin, Spain \\ ${ }^{2}$ DLR Architects, USA \\ ${ }^{3}$ College of Architecture, University of Nebraska, USA \\ ${ }^{4}$ Despang Architekten, Germany
}

\begin{abstract}
"Sustainability," being the buzzword of the 21st century, is particularly challenging to the current generation, now in their early teens, which grew up with a childhood of lackadaisical use of fossil energy. This generation, which will soon be leading the world, has been inappropriately labelled the "generation me" and is expected to prove its successful transitioning into "generation $\mathrm{p}$ [ostfossil]." If the young emerging architectural professionals choose, they can be the mission group in helping reduce the overall fossil footprint that buildings contribute to the world by $40 \%$. The young professionals, however, must be proactive because developers and contractors increasingly target low or no emission structures. While their energy performance is undoubted, their architectural performance is questionable. An architecture student at the University of British Columbia recently and most appropriately addressed this dilemma in a much more unplugged way, "...you guys screwed up everything and we are supposed to fix it...." This paper investigates two major missions: first, and most important, how to get the upcoming architectural generation $\mathrm{p}$ (ostfossil) excited about the topic of bioclimatic design, and second, where to begin in the future to create a sensitive and intuitive understanding for both the poetics and pragmatics of eco- and archi-friendly architectural design.
\end{abstract}

Keywords: K12 design, bioclimatic educational design, developing aid design, generation ( $p$ ostfossil), brettstapelbauweise, timber modification technology. 


\section{Introduction and analysis}

As an international collaborative and cross-cultural study, authors Dr. Sandra Costa Santos, Gerold Klein, and Associate Professor Martin Despang have identified "human event and activity in space" to have potential for an improved sustainable life to be built from the bottom up. By exposing young people as early as possible to a living in balance with nature and the elements in decency and style, a solid societal basis for bioclimatic regeneration of the built world is achievable.

The architectural building type of educational design serves as a vehicle to transport the eco- and archi- friendly value system, and becomes a means to widely distribute and deeply anchor these values in society from an early age.

The synergistic and effective method to achieve the injection of values into society can be seen in the immediacy of architectural design: building carbon neutral kindergartens and schools, as well as using the academic freedom to push the architectural and environmental bar as high as possible. By utilizing this creative knowledge to consult and coach young architecture students to design these facilities, the students are then considered to be the best experts, as they employ sensitivity or the essentiality of bioclimatic spaces and places as early as possible in their careers. This paper uses both academic and professional case studies to illustrate this pedagogical method. Dr. Costa Santos will explain her internationally respected pedagogies, along with her recent third year studio design probe of a local school in La Coruna/Spain.

Following, the paper will cover DLR / Omaha, Nebraska, as the leading designers of schools in the USA, and their collaboration with Professor Despang's University of Nebraska - Lincoln's students', for the design of a School in Gulu, Uganda. The paper concludes with a critical assessment of the ILMASI school for mentally disabled children in Garbsen / Germany, designed by Despang Architekten, which utilizes innovative, typological, technological and tectonic strategies relating to solid wood and thermally modified timber, which have been critically reflected on and researched by Dr. Costa Santos.

\section{Educational case study: CESUGA Spain}

The primary school is the first major design project that third year students have to tackle in the School of Architecture in CESUGA [2]. The school follows University College Dublin's program of studies with some variations required by the Spanish government. This is a five-year academic course, with a completion of a bachelor degree after the third year. Therefore, the third year is an important milestone for the architecture students to prove a certain level of competence and expertise. The school's culture is strongly studio-based, understanding the studio not just as a place for design, but as a place for comprehensive design where much of the knowledge learned by the students through the lecture series has to be applied, tested, and explored through their own projects. The lecture series covers building technology, structural design, building services, architectural ecology and conservation, and history and theory of architecture. The third year 
studio program brings students closer to the architectural character and representation of institutions and collective and civic architecture by managing issues of scale, landscape, territory and graduation from private to public space in society. The students have to develop the ability to consider the needs of the individual and those of the collective and have to recognize the expressive public nature of collective buildings by representing in the city the values and ideals of the community. Following our school's ethos, the design studio program is strongly based on the idea that structures, building technique, ecology and understanding of materials are part of the design process. The students are asked to use a broad range of skills and techniques, including hand and computer drawing, model making, and other means to make legible their design approaches.

Over the course of seven weeks during the 2008-2009 term, the students had to think, explore, and investigate to design a primary school in Ourense. Ourense has a population of over 107,000 inhabitants and is located in Galicia along the river Minho valley in northwest Spain. Considering the huge amount of gold that the valley used to have, it was called Auriense, meaning "the gold city", by the Romans who built a bridge over the Minho (this was later rebuilt in the 12th century). Thus Ourense became an important city of Hispania until the shortage of gold in the river. Due to its strategic position, this bridge held a lot of traffic during the Middle Ages. When the railway came to Ourense in the 19th century, the development of the city would point towards retail and administration. After the Spanish Civil War from 1936-1939, Ourense's growth admitted strong immigration from rural areas. Today, the city remains as an administration and trade centre. Its local microclimate offers humid, cold winters and humid, hot summers. The site for the primary school was located along the Minho River, between the Roman bridge and the contemporary Millennium Bridge. During the duration of this exercise, the pedagogies applied by the tutors pursued a series of objectives including the understanding of place, spatial ambition through the development of the architectural program, and the integration of structures, construction, and ecology. The methodology used in the studio offers the

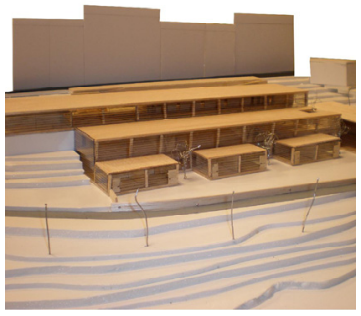

(a)

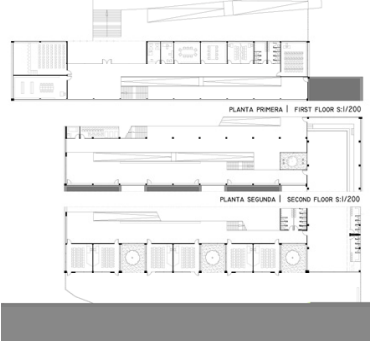

(b)

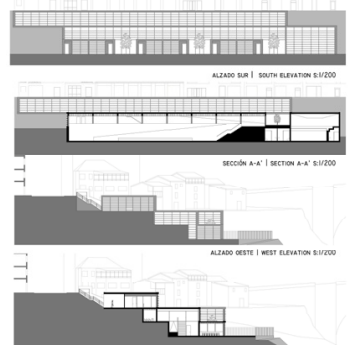

(c)

Figure 1: (a) Ourense primary school; (b) organization in plans; and (c) sections. 
students some indication of direction, leaving students to find their own solution based on group and individual work, group reviews, precedent studies, discussions with school teachers, and critiques with invited professors. Associate Professor Martin Despang kindly offered his experienced views on schools and joined in the studio tutorials in January 2009.

The first step the students are asked to take is the site analysis. The site analysis runs along seminars on Ourense within the history lecture series. The students begin with a site visit that allows them to take data such as photographs, notes, sketches, survey elevations, plans and sections. This analysis is followed by various studies that aim towards grasping the site's morphology, the way it is influenced by (and influences) its environment, its role within the community's activities, and its needs and values. This step should naturally lead the student to propose a site strategy.

Once they have analyzed the site, they study precedents and visit schools, where they have the chance to hear from the teachers how schools work or should work. By this point, they should be in a position to work with the program they were given. Working with the program involves a degree of critical thinking since the question is not as much meeting a required accommodation as it is achieving a good and inspiring environment for the children and the community in which they belong. Third year students are expected to translate a given brief into added value for the school users. Understanding the brief allows the students to develop their site strategy into a building strategy or conceptual design.

During the following weeks, the students are asked to develop their project through several scale jumps and assess it during interdisciplinary studio seminars (structures, construction and ecology). At the end of this process, a successful student project will offer an architectural educational space based on a sensitive understanding of construction, structures and ecology. The methodology used in the studio proves that students asked to "work with and for" the site from an early stage helps deliver sensible spatial solutions in terms of community interaction, resources, and construction. Integrating technology and ecology within the overall project strategy not only adds spatial value (making the whole proposal more sound), but can also increase energy efficiency

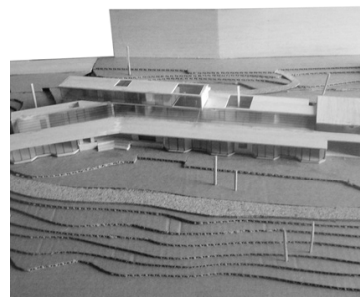

Figure 2:
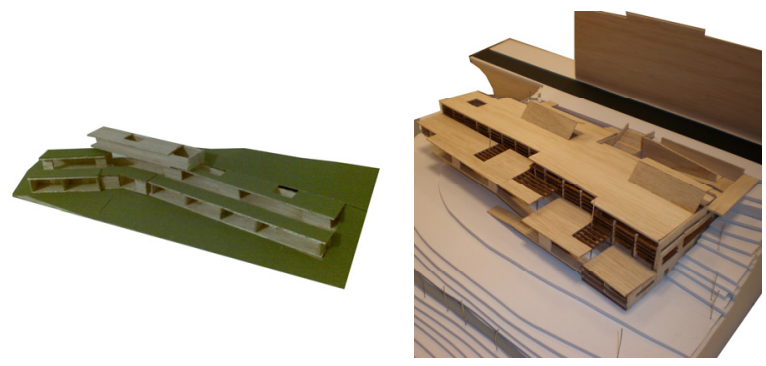

Versions and options of eco-tonics. 
(enhancing good natural lighting, helping crossed natural ventilation and using materials with thermal mass, for instance). Educating young architects-to-be at an early stage on taking responsible bioclimatic decisions can prove vital to preserve our environment.

\section{Educational case study: Jesuit School/Gulu Uganda Africa}

Through DLR Group's [3] relationship with Creighton Prep, a rapport was developed with Father Tony Wach. As a result, DLR's passion for K-12 design and the intrigue of an unfamiliar culture and environment was revealed. A team was formed to pursue Father Tony's vision of providing educational opportunities for the youth in northern Uganda/Africa in form of a school to be located in the southeastern part of the country, four miles east of the city of Gulu.

\subsection{Society of Jesus (Jesuits)}

The tradition and mission of the Society of Jesus (Jesuits) is "to be in solidarity" with suffering brothers and sisters, particularly through prayer and spiritual ministries, advocacy, and financial assistance. In the northern region of Uganda, 20 years of terrible insecurity has broken down the culture, family life, morale, health, economy and education. In accordance with their mission, the Jesuits plan to construct a boarding school to accommodate 1,200 boys and girls. The curriculum will consist of liberal arts and vocational schooling, working towards repairing the broken way of life in the area. Given the remote location, the campus will use sustainable strategies such as on site brick production, solar energy and water harvesting for farming or gardening, all together maintaining the quality of life for its residents.

UNL strives to find studio projects that are relevant to the global condition, along with working with firms to expose the students to architectural practice.

The Project was welcomed by the University of Nebraska-Lincoln's College of Architecture [1] Dean Drummond and embraced by Professor Despang who, in his home country of Germany, is a registered architect and partner of Despang

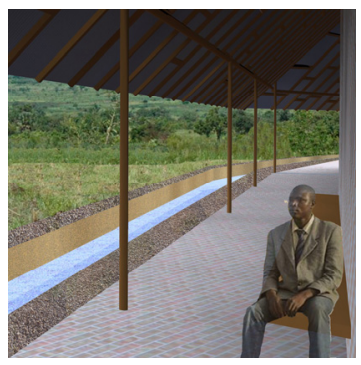

(a)

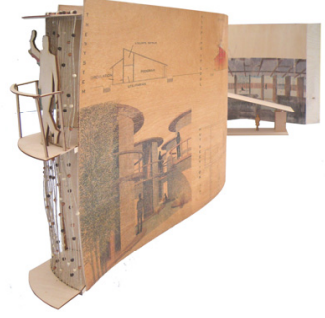

(b)

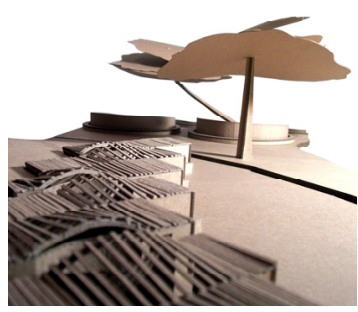

(c)

Figure 3: (a) Andy's socializing; and (b) private spaces; (c) Kelly's arboretum. 
Architekten [4]. Despang Architekten, located in Hannover, Dresden and Munich, Germany, is renowned as an innovator in K-12 and sustainable design, thus making Professor Despang a good partner with DLR Group. The studio culture instilled by Professor Despang and Professor Erhard Schütz is one of a lab environment focusing on the exploration of new technologies and materials. Given DLR Group's expertise and experience, they were teamed together, incredibly excited about the possible learning opportunity.

DLR, the leader in K-12 designs in the USA and an emerging innovator in sustainability, wished to share their expertise with future architects at an academic level. DLR Group principal and Representative Gerold Klein worked side by side with Professor Despang in guiding the students through their individual research and design process. The interaction showed the students that design could be their future in a way to make a difference in the world. Klein's vast experience with DLR Group showed to be very beneficial to the students during the exploratory process, especially since he was making them aware of the pragmatic as well as poetic aspects of design, encouraging them to design in synergy of both.

The fundamental challenge and experience of the studio for all participates, mentees, and mentors was to step out of their cultural comfort zones, from the point of view of comfortable developing countries and cultures with amenities and comfort, down to an opposite environment which lacks the basics of human existence. It became an investigation of the "essentials", questioning how much an individual and its solidifying communal entity absolutely needed to provide decency and spatial dignity. In the region of Gulu, this primarily meant shelter from the harsh extremes of the elements of sun and rain. Each student had to take into consideration the culture, climate, typology, vernacular, and materiality. The ultimate goal was then to select tectonics and materials that were plausible for either being locally available or brought in with careful consideration of the appropriateness in terms of effort, cost, and carbon footprint. The students and instructors, coming from a culture of "plenty", struggled with this and were quickly aware of their thoughtlessness in their own capitalistically driven context, where the way they build is not driven by logical and resource related

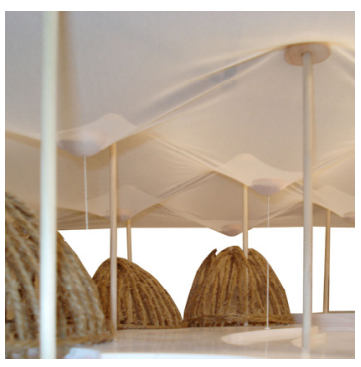

(a)

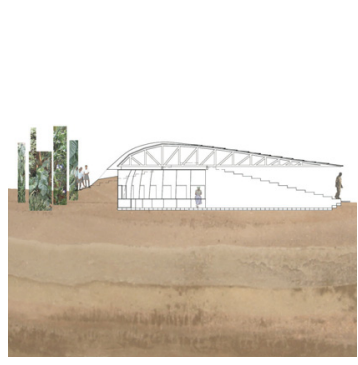

(b)

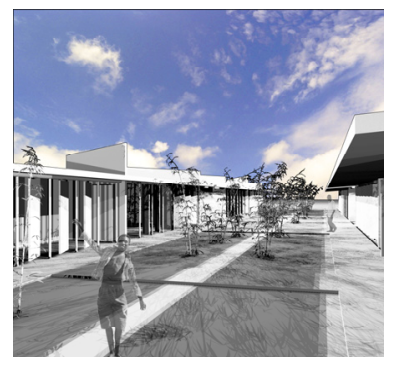

(c)

Figure 4: (a) Chris's canopies; (b) Sara's mounts, (c) Nate's communities. 
conscious parameters, but rather the forces of unrestricted markets. These markets then sell products like natural stone, for example, an attractive but yet cheap building cladding material; the natural stone, however, comes with the high price of being carved out of the earth by child labour in underdeveloped countries and the price of shipment with extreme carbon footprints. This case is similar to privileged people buying new laptops, their old one being shipped to Africa where underprivileged, young children burn them under the open sky to extract the metal parts and sell them back to the developed world, wasting their health and drastically shortening their life expectations during the process.

The studio therefore began to realize that thoughtful design for the minimum demand with the minimum means could be a method that could possibly be meaningful beyond the Gulu School. This realization would be an educational impact for all of the students.

All of the designs for the Gulu School provided sun and rain protected spaces as well as the incorporation of thermal mass. This combination can provide the decent physical background to allow the users to be intellectually and spiritually challenged to become better-educated citizens who continuously use their improved skills to elevate the societal quality of life. The school design to this broadened extent has the power to fundamentally change society for the better.

By the end of the studio, the students left with a new appreciation for the profession's potential for intercultural, ethical, and humanitarian responsibility as well as the architects role to help by sharing the excellence of their own culture while at the same time respecting and interpreting the local culture. The project was a great learning opportunity for both academia and the professionals.

\section{Professional case study ILMASI School/Garbsen Germany}

The ILMASI School [5] by Despang Architekten can be seen as an assessment control application of the pedagogical and societal goals of the academic methodologies at CESUGA and UNL/DLR in Gulu. The task was to design a built environment that is responsive to the needs of a just begun post fossil $21^{\text {st }}$ century in making it as bioclimatic in its broadest possible way of life cycle consideration. At the same time it aimed to achieve the highest building culture

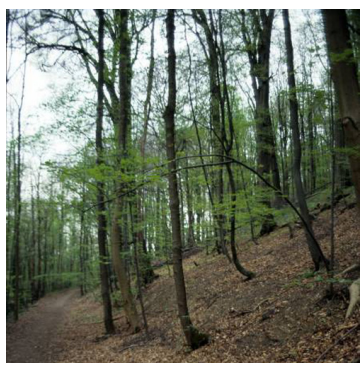

(a)

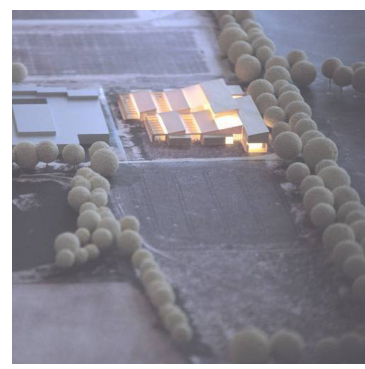

(b)

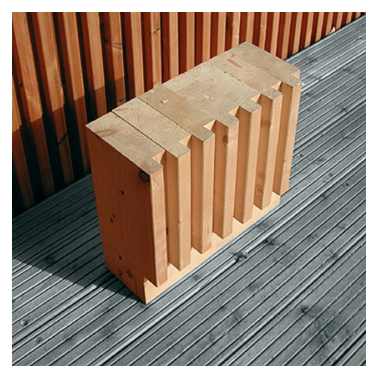

(c)

Figure 5: (a) Concept nature; (b) concept macro; (c) concept micro. 
achievements, which seek synergy of environmental and architectural excellence. In terms of its social responsibility, as much as the school near Gulu provides decent space for the poorest and most underprivileged, the ILMASI does this for an equal group of people in the developed country of Germany who need the most and special care, as these are mentally disabled children.

ILMASI stands for "integrated learning with all senses", which describes the pedagogical idea to stimulate these children in a multi-sensatory way, in direct response to their needs to be addressed beyond the visual sense - which is what school design and architecture conventionally does in contemporary educational design. Design decisions regarding the structural, mechanic, tectonical and materiality choices in K12 design are supposedly made by parameters of efficiency and effectiveness, which usually leads to the most streamlined results without addressing multi sensitivity but rather a "value engineering" in bringing the down to the profit driven basics as opposed to the essentials of complex simplicity. Although under a conventional capped budget for this civic building type, the search, in a way very similar to the Gulu School, went for a system with one essential, locally available material which could do it all, including catering to the 5 senses and assuring a very practicable low maintenance and utility cost reducing building at the same time. The idea was born out of the analytical question presented to the school board asking what the ideal place for the children to be in was. Their quick response was a forest, because of the variety within a systematic structure and the ability to soothe air and soul. The architectural abstraction became a structural system of surface notched wooden boards nailed together to structural slabs, which were anonymously applied to walls and ceilings in a seamless manner to create the inner surface.

In terms of the multi sensitivity, sound is absorbed by the louvered texture, whereas light and shade play with the eyes. Walking by and touching the thermal mass balancing wood resonates in the fingers and the humidity absorbing nature provides a gentle smell and occasionally occurring resin can even be tasted.

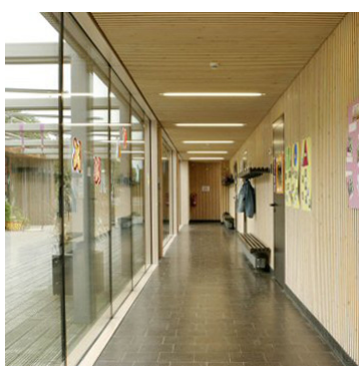

(a)

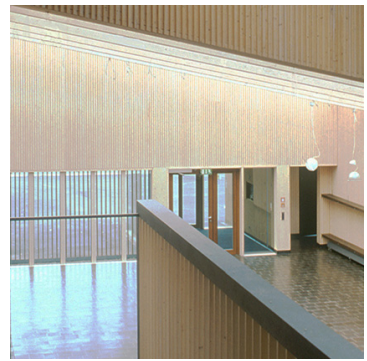

(b)

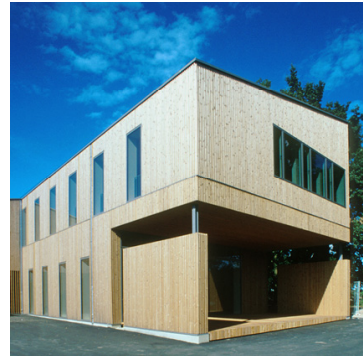

(c)

Figure 6: (a) Walk in the woods; and (b) internal clearings; (c) architecturalized. 
Against prejudice, using wood in an intensive way is sustainable because, as a local renewable resource, it encourages the replanting of trees and forests, which helps convert carbon dioxide into oxygen.

In terms of the embodied "evidence base design" factors most valuable trait is that at the recent fifth anniversary a significantly improved physical and psychological/spiritual health improvement of the children was confirmed. This can be credited to the inclusive tectonic system in collaboration with the systematic layout that maximizes exposure to daylight and sun in parts through UV admitting ETFE roofs and the injection of outdoor courtyard spaces with fresh air exposure.

The client, being the Regional Municipality of Hannover, also reported that the utility cost of the building was significantly low due to the thermal properties of the wood and the extra insulation behind a maintenance free rain screen of TMT (Thermally Modified Timber), which keeps the energy inside through closed north facades and increases passive solar gain with optimized southern solar exposure. To the long-term surprise of the client, the exposed, solid wood wall surfaces have shown a significantly lower maintenance demand than the conventional intent of efficiency and effectiveness of the selected plastered walls. The multi-sensual qualities have also more than outperformed common brick and CMU wall systems. Although the building costs have been in the same range as the comparable solid, stereotomic buildings, the maintenance costs have been significantly lower and the comfort and appreciation level exponentially higher.

The ILMASI School has proven itself to be unconventional and nontraditional with cutting-edge conceptual and materialized design strategies, customized to the specificity of the educational clients needs as a valid design method in the field of educational facilities. The project's wide recognition and reception by an international research community, kindly including Dr. Costa Santos with relevance of typological wood technology with application of her $\mathrm{PhD}$, had motivated Despang Architekten to continue to work likewise with a variety of following projects: an all day school addition in exosceletonic concrete, a kindergarten in cellulose insulated light weight wood, and a currently under construction thermal massing, earth burned concrete kindergarten for Germany's oldest University of Göttingen.

\section{Conclusion}

Educational architecture is the very best investment for the future because of the sensitization by young people for both ecologically and architecturally performing spaces and places having the potential to be an essential impact on the global environment.

Educational facilities, besides dwellings, are most personal and emotional in terms of occupational intensity, providing them with the most power to positively influence people's attitude towards bioclimatic principles. Whereas dwelling types exclusively reach the individual only, educational facilities typology inclusively addresses many members of society and has a tremendous 
potential of pedagogical capability in terms of their way of teaching about post fossil living through the way the buildings are conceptualized. The method to let the youngest generation of terrestrials grow up in built environments with the lowest carbon and largest architectural values possible leads to a natural positive bioclimatic conditioning, which enables them to intuitively operate on an environmentally progressive basis.

Strategically speaking, the most effective ideal is to have the current generation of young architects in training engage in the typology of education design, so that their future children can grow up in bioclimatic environments, widely spreading this progressive post fossil lifestyle. The necessary motivational means to get them excited to look back that early into their lives at their just escaped childhood is to allow and encourage the design of educational buildings to be more critically cutting-edge and as fun as other building typologies.

Maybe then the synthesis of the education of ecological architecture through the foundation of ecological educational topology will have a multiplying effect of the soon to be disciplinary generation $\mathrm{p}$ [ostfossil] in charge, taking effective and joyful responsible leadership for their millennium.

\section{References}

[1] University of Nebraska College of Architecture, http://archweb.unl.edu

[2] CESUGA - University College Dublin, www.cesuga.com

[3] DLR Group, www.dlrgroup.com

[4] Despang Architekten, www.despangarchitekten.de

[5] www.imagineschooldesign.org

[6] Institut für Holztechnologie Dresden/Institute for Wood Technology Dresden, www.tmt.ihd-dresden.de 